Eixo Temático: Relação entre Ciência, Educação e Cultura

\title{
ET-05-005 \\ OS RÉPTEIS E SUA REPRESENTAÇÃO SOCIAL: UMA ABORDAGEM ETNOZOOLOGICA
}

Diego Filipe Silva Araujo, Janaina Maria Pereira, Karla Patrícia de Oliveira Luna, Nathalya Marillya de Andrade Silva

Universidade Estadual da Paraíba - UEPB. Centro de Ciências Biológicas e da Saúde - CCBS

http://dx.doi.org/10.21472/congrebio2016.et-05-005

\section{RESUMO}

Este trabalho possui como base de estudo a etnozoologia ciência a qual tem como objetivo o estudo do conhecimento da população sobre os animais, e é um recorte do trabalho de conclusão de curso intitulado "A influência do folclore na percepção social referente aos répteis”, este estudo investigou o quanto a cultura popular e a falta de uma educação ambiental podem influenciar na representação social referente aos repteis, a pesquisa foi realizada através de uma amostra da população da área urbana do município de Campina Grande no estado da Paraíba, os resultados apresentados na pesquisa foram obtidos através de questionário estruturado, ao qual teve como critério para a participação da pesquisa, que os participantes possuíssem idade igual ou maior que 18 (dezoito) anos e ser residente da área onde foi realizado o estudo, a entrevista foi realizada aleatoriamente em praças, bares e ruas, no intuito de obter uma amostra diversificada da população. Com os resultados obtidos, foi possível realizar uma análise da relação cultural e o nível de educação ambiental existente entre a população local a respeito dos répteis da região. Apesar da metade dos participantes (50\%) terem consciência de que esses animais são importantes para o meio ambiente, um total de $65 \%$ dos entrevistados afirmou temer esses seres, contudo, esse medo relatado das pessoas ligado a mitos, equívocos culturais e juntamente com a falta de uma ciência educadora, influencia diretamente em atos de extermínio desses animais, isso pode ser verificado através dos dados obtidos, onde, quase metade dos participantes (45\%) afirmaram realizar ou pedir para alguém realizar o extermínio desses animais quando se sentem ameaçados ou por falta de informações sobre esses seres. Com a obtenção desses resultados, foi possível concluir após a realização do estudo e análise dos dados que a falta de uma ciência ativa para educação ambiental e a cultura baseada nas crendices populares, encontram-se intrínsecas na população urbana. Esta conclusão é importante, pois contradiz o senso comum de que as crendices são características apenas das áreas rurais, inexistentes no meio urbano.

Palavras-chave: Repteis; Cultura; Educação Ambiental.

\section{INTRODUÇÃO}

Interações entre os seres humanos e animais de outras espécies ocorrem desde os primórdios da humanidade e foram evoluindo ao longo do tempo. Cerca de 99\% da história evolutiva do homem, está profundamente envolvida com outros seres vivos, desta forma os seres humanos desenvolveram um significativo sistema informacional com relação as espécies e o ambiente, que se traduz nos saberes, crenças e práticas culturais relacionados com a fauna de cada lugar (SAX, 2001).

Marques (1995) afirma que as interações entre homens e animais estabelecem uma das conexões básicas que toda e qualquer sociedade mantém com o universo, sendo fortemente 
expresso pelas pinturas rupestres que inclui figuras de animais selvagens, assim como diversas pinturas de homens em suas atividades de caça.

Relações entre educação, ciência e cultura, fizeram e ainda se fazem bastante presentes nas interações entre os seres humanos e os animais. No Brasil, por exemplo, espécies de animais (incluindo os répteis) têm sido utilizadas medicinalmente pelas sociedades indígenas há milênios. Durante sua viagem pelo interior do Brasil no século XIX, Von Martius (1939 apud ALVES, 2008) gravou muitos medicamentos naturais utilizados pelas tribos ameríndias que ele encontrou.

Conforme afirma Souto (2014), as interações entre as espécies ocorrem desde que o homem ainda nem homem era, referindo-se a circunstância de que quando isso se iniciou o homem ainda não teria evoluído para Homo sapiens sapiens. Desta mesma forma o autor também comenta que:

As interações foram se diversificando tão intensamente como a própria evolução cultural, social e tecnológica dos homens. Temos hoje relações do tipo trófica, econômica, afetiva, mítico-religiosa, médica, lúdica, simbológica, estética, artística, ergonômica, entre outras, cada uma, aliás, com uma infinidade de possibilidades.

O que as pessoas acreditam sobre a relação homem e animal determina suas atitudes que podem ser explicadas pela presença cultural e valores negativos sócio-demográficos sobre determinadas espécies (CERÍACO, 2011).

Ceríaco (2011) também afirma que as causas da perseguição humana de animais têm naturezas diferentes e a existência de um grande número de mitos, histórias e equívocos (alguns deles resultantes da interpretação direta da cultura local) pode ser em grande parte responsável por algumas destas perseguições. Este mesmo autor ainda menciona que resultados de pesquisas apontam uma maior perseguição humana de anti-conservação com relação a répteis e outros, que tem como explicação a presença de folclore e valores negativos.

Desta forma a Etnozoologia baseia-se como o estudo do conhecimento da população sobre os animais, esta ciência faz parte de um campo de estudo mais abrangente, denominado de Etnobiologia, ao qual foi definida como a ciência que procura compreender como comunidades tradicionais (indígenas, quilombolas, pescadores e agricultores) percebem, classificam e constroem o ambiente (SANTOS-FITA e COSTA-NETO, 2007).

Apesar de lidar com uma área muito vasta e importante dos tipos de relações humanas com animais, estes estudos ocorrem em todo o mundo, porém não são muitos (CERÍACO, 2011). Contudo estes trabalhos têm apresentado grande destaque para as regiões Norte, Nordeste e Sudeste do Brasil (ALVESe SOUTO, 2010).

\section{OBJETIVOS}

\section{Objetivo geral}

O presente trabalho teve como principal objetivo identificar a percepção de pessoas na cidade de Campina Grande no estado da Paraíba a respeito dos répteis, a fim de obter resultados que possam comprovar se existe a influência cultural a respeito da percepção e perseguição destes animais pelo ser humano e também averiguar o déficit no nível da educação ambiental da população, ciência bastante importante para a preservação do meio ambiente e dos animais presentes nele.

\section{Objetivos específicos}

Identificar as percepções, concepções, relações culturais e conhecimentos científicos de um grupo de participantes escolhidos aleatoriamente em locais públicos do município de Campina Grande na Paraíba, a respeito dos repteis da região; Analisar a partir das respostas presentes em questionários, se os participantes conhecem a importância da preservação e dos 
benefícios dos répteis; Avaliar se a cultura pode determinar atitudes negativas contra as espécies, favorecendo atitudes de anti-preservação e verificar a existência de um déficit no conhecimento cientifico e na educação ambiental da população.

\section{MATERIAIS E MÉTODOS}

\section{População de estudo}

A presente pesquisa foi realizada na zona urbana do município de Campina Grande no estado da Paraíba, os participantes foram selecionados aleatoriamente em locais públicos, bem como: praças, lojas, cafés e casas em vários locais do estudo, com o objetivo de obter uma amostra representativa da população.

Teve como condição prévia e indispensável para poder participar da pesquisa, ter idade igual ou maior que 18 (dezoito) anos.

O contato com os participantes e a aplicação dos questionários foi realizado no período de abril de 2015 a julho de 2015. Antes de iniciar a coleta de dados foi explicado a cada participante o objetivo do trabalho a ser desenvolvido.

O indivíduo que aceitou participar da coleta de dados através dos questionários, foi orientado a assinar o Termo de Consentimento Livre e Esclarecido (TCLE), Protocolo $\mathrm{N}^{\mathrm{o}}$ 45226214.5.0000.5187, previamente autorizado pelo Comitê de Ética, da Universidade Estadual da Paraíba (UEPB).

\section{Questionário estruturado}

Os dados para a pesquisa foram obtidos através da aplicação de questionário estruturado, ao qual foram constituídos de questões fechadas (objetivas), onde para cada item seria necessário que o participante respondesse: SIM, quando o mesmo concorda com a alternativa; NÃO, para quando discorda da alternativa; NÃO QUERO RESPONDER, para quando o participante não quer ou não sabe responder a questão.

Os questionários abordaram perguntas referentes ao conhecimento dos participantes em relação aos grupos de animais trabalhados, questões relacionadas a valores positivos e negativos a respeito dos repteis e também questões relacionadas à perseguição, preservação e importância ecológica. Durante as entrevistas todos os questionários foram acompanhados de um folheto demonstrativo com exemplos de grupos de animais abordados na pesquisa, bem como: lagartos, serpentes, anfisbenas, quelônios e jacarés.

\section{Análise dos dados}

Os dados dos questionários estruturados obtidos através de entrevistas com os participantes foram contabilizados e transferidos para planilhas do programa Excel e analisados matematicamente por meio de porcentagem ao qual depois foram transformados em gráficos para uma melhor compreensão. No total foram entrevistados 60 (sessenta) pessoas entre homens e mulheres.

\section{RESULTADOS E DISCUSSÕES}

Com a interpretação de cada item dos questionários foi possível obter dados necessários para uma análise se a cultura pode influenciar na percepção e representação social da população a respeito dos repteis, também foi possível averiguar de forma parcial o conhecimento dos entrevistados sobre esses animais, verificar se existe um déficit na educação ambiental a respeito da importância desses animais para o meio ambiente, também foi possível observar o quanto esses animais podem ser repulsivos ou até mesmo admirados por uma amostra da população.

$\mathrm{Na}$ questão relacionada ao conhecimento sobre os répteis, foi perguntado aos participantes se esses animais são úteis aos seres humanos, um total de $20 \%$ dos questionados afirmaram que esses animais não são úteis para o ser humano e responderam não para a 
respectiva alternativa, resposta essa que pode ser resultado da falta de informação sobre os seres em questão, ou até mesmo pela transmissão do conhecimento popular passado de geração a geração.

Na mesma questão, 30\% dos entrevistados optaram por marcar não sei ou não quero responder, o que aponta indecisão dos participantes ou até mesmo mostrando a falta de conhecimento do entrevistado frente ao questionamento proposto. Por outro lado, $50 \%$ dos participantes consideraram os répteis extremamente importantes para os seres humanos (Gráfico 1).

Na verdade esses animais possuem papel de grande importância no funcionamento dos ecossistemas brasileiros, sendo úteis para o controle de insetos, bem como realiza as anfisbenas, a maioria dos lagartos, algumas espécies de serpentes e algumas espécies de tartarugas que são consumidores secundários, além das espécies folívoras, como as iguanas, vários outros lagartos consomem frutos e podem atuar como dispersores de sementes para várias espécies de plantas (MARTINS e MOLINA, 2008).

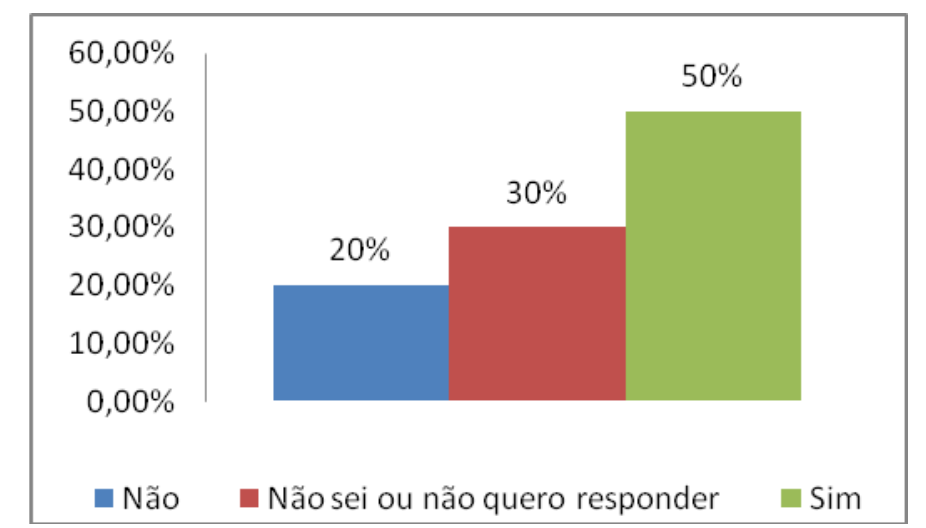

Gráfico 1. Pergunta: Esses animais são úteis ao ser humano?

Na questão seguinte relacionada ao conhecimento sobre os repteis, quando os participantes foram perguntados: Esses animais são em sua totalidade perigosos? Um total de $70 \%$ das pessoas que participaram da pesquisa afirmou que esses animais são perigosos (Gráfico 2), já os que afirmaram ter medo de répteis totalizou 65\% (Gráfico 3).

Estas informações precipitadas sobre estes animais são provenientes desde os primeiros conhecimentos adquiridos por parte da população, erros conceituais em relação a esses animais estão presentes desde a escola, nos livros didáticos, fazendo com que conceitos equivocados perpetuem (COSENDEY e SALOMÃO, 2013).

Conforme mencionado anteriormente, durante a aplicação dos questionários, foi demonstrado aos participantes um folheto contendo imagem de alguns repteis para que as pessoas pudessem verificar exemplos desses animais, para esta questão, foi possível interpretar também que o maior receio e medo das pessoas foram referente às serpentes, o que pôde ser observado durante a aplicação dos questionários onde muitas pessoas expressavam repúdio ao visualizar a imagem deste animal no folheto demonstrativo, os entrevistados não levaram em consideração outras imagens de animais que não são peçonhentos ou agressivos, como por exemplo, os quelônios apresentados, cágado (Mesoclemmys tuberculata), jabuti (Chelonoidis carbonária), e outras espécies também presentes nas imagens.

Segundo Freitas (2003), o medo e os atos de matanças desses animais ocorrem devido à falta de informação de algumas pessoas, que por acreditarem que as serpentes são animais desprezíveis e extremamente perigosos, optam por matá-las sem ao menos separarem o que é mito do que é realidade. O autor acrescenta que esse raciocínio lógico é fruto de uma educação mal executada durante décadas em nosso país.

Sendo assim pode-se entender que estes animais são exterminados para que sejam eliminadas as ameaças e os riscos que a população acredita que esses animais proporcionam, 
conceitos equivocados adquiridos a partir da cultura local passada de geração a geração e por meio da falta de uma educação ambiental, isso foi constatado quando os participantes foram perguntados: Quando vejo algum desses animais mato ou peço para alguém matar?

Quase metade dos participantes (45\%), afirmaram realizar ou pedir para alguém realizar o extermínio desses animais (Gráfico 4), este fato ocorre devido o medo das pessoas em relação aos répteis e, principalmente, aos répteis peçonhentos como os ofídios. Este medo é resultante de diversas historias e mitos que circundam esses animais, isso faz com que muitas serpentes e outras espécies de répteis sejam mortas na tentativa de legítima defesa por parte do ser humano, apesar da maior parte dos acidentes serem causadas devido à imprudência humana (COSENDEY e SALOMÃO, 2013).

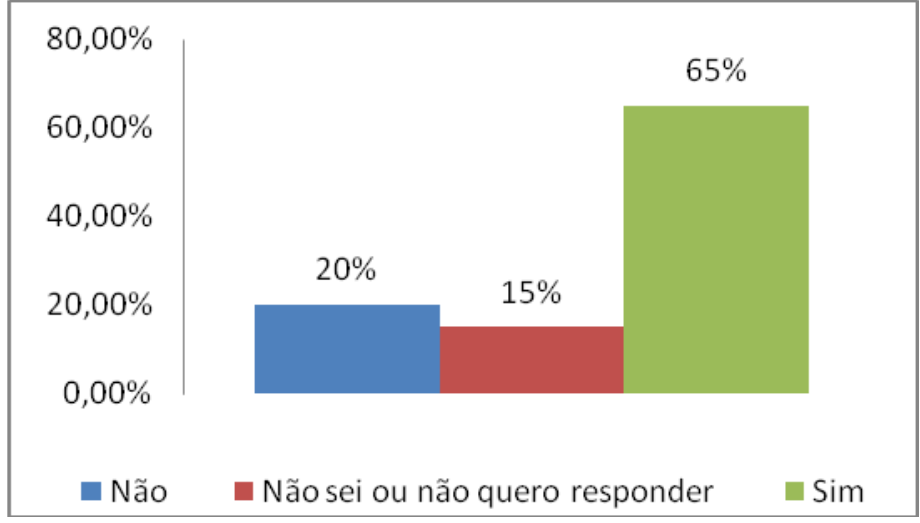

Gráfico 2. Pergunta: Eu tenho medo desses animais?

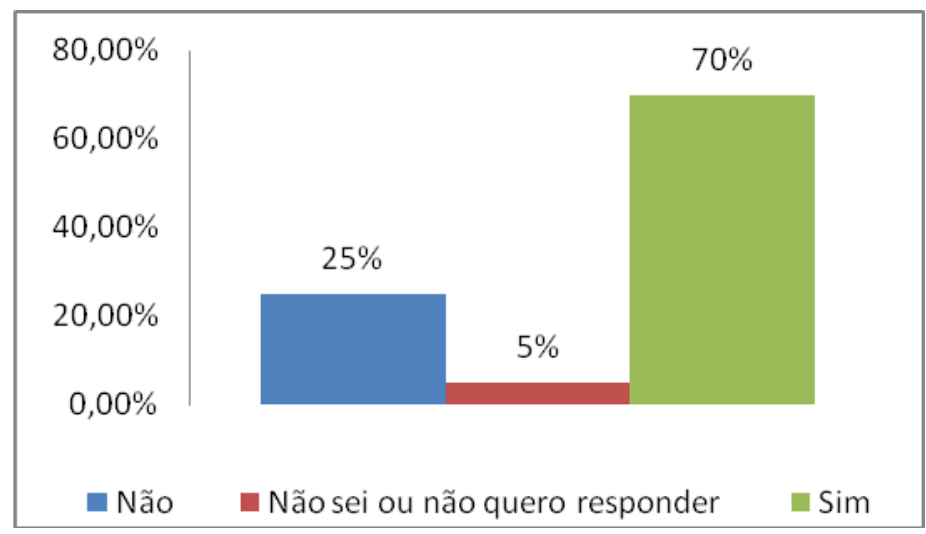

Gráfico 3. Pergunta: Esses animais são perigosos?

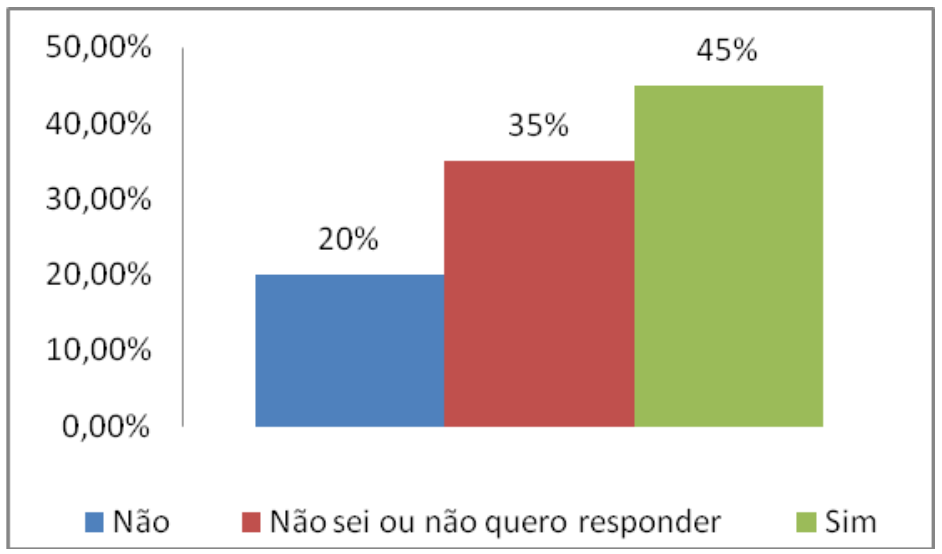

Gráfico 4. Pergunta: Quando vejo algum desses animais eu mato ou peço para alguém matar? 
Os atos de extermínio dos répteis são maiores quando esses animais são encontrados no ambiente domestico isso foi verificado quando os entrevistados foram questionados: Se existe população desses animais em minha propriedade, tomo medidas para exterminá-los?

Um total de 65\% afirmou tomar medidas de extermínio contra esses seres quando os mesmos são encontrados nas suas propriedades (Gráfico 5).

Pode-se perceber um aumento de $20 \%$ quando esta questão é comparada com a anterior a qual as pessoas informaram matar ou pedir para alguém matar esses seres. Na questão anterior não foi especificado o ambiente da presença dos animais na questão (Gráfico 4).

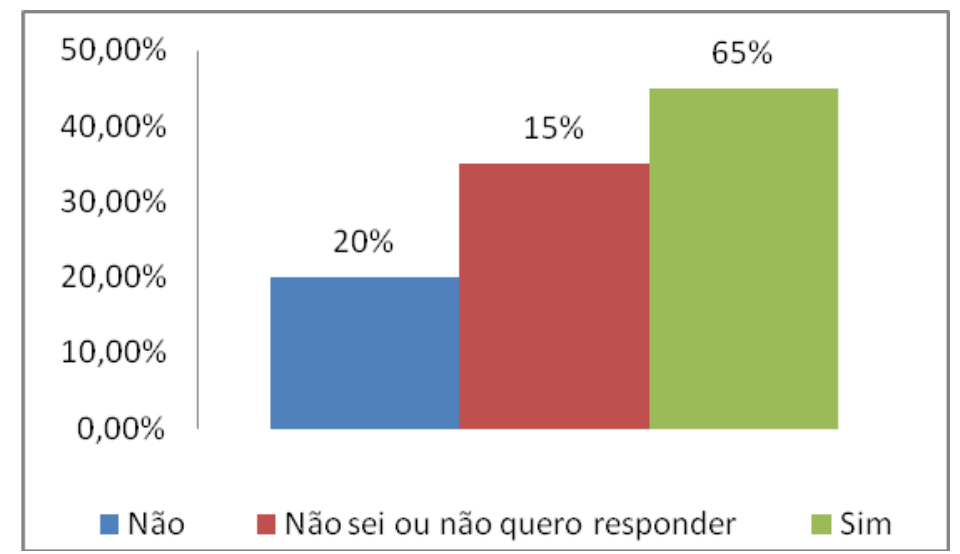

Gráfico 5. Pergunta: Se existe população desses animais em minha propriedade, tomo medidas para exterminá-los?

\section{CONCLUSÕES}

Após a aplicação dos questionários e análise dos dados, foi possível perceber que os conhecimentos prévios baseados nas crendices populares, mitos, e equívocos, encontram-se presentes nas populações urbanas e rurais. Esta conclusão é importante, pois contradiz o senso comum de que as crendices são características apenas das áreas rurais, inexistentes no meio urbano.

É fato que a destruição de habitat, poluição e mudanças climáticas colocam em risco a sobrevivência dessas espécies, mas é também conhecido que a complexa relação entre homem e esses animais, consiste em uma perseguição constante, através da captura, abate e atos de extermínio, como pode ser verificado nos resultados desta pesquisa.

Sendo resultado da crescente urbanização, o contato com esses animais tornou-se cada vez mais comum. Além da preocupação com a fauna, há ainda o problema de saúde pública, a divulgação de medidas de primeiros socorros inadequadas para acidente com répteis peçonhentos como as serpentes, isso pode levar a sérios problemas de saúde.

Desta forma torna-se claro a necessidade de medidas que proporcionem uma educação ambiental e também aproximar mais objetiva a ciência da comunida para que possam ser evitadas futuras extinções das mais variadas espécies de répteis e outros animais.

\section{REFERÊNCIAS}

ALVES, R. R. N.; VIEIRA, W. L. S.; SANTANA, G. G. Reptiles used in traditional folk medicine: conservation implications. Springer Science, v. 17, n. 8, p. 2039-2043, 2008.

ALVES, R. R. N; SOUTO, W. M. S. Panorama atual, avanços e perspectivas futuras para a etnozoologia no Brasil. In: ALVES, R. R. N; SOUTO, W. M. S; MOURÃO, J. S. A Etnozoologia no Brasil: importância, status atual e perspectivas. 1 ed. Recife: NUPEEA, 2010. v. 7. p 19-25. 
CERÍACO, L. M. P.; MARQUES, M. P.; MADEIRA N. C.; VILA-VIÇOSA, C. M. M.; MENDES, P. Folklore and traditional ecological knowledge of geckos in southern Portugal: implications for conservation and science. Journal of Ethnobiology and Ethnomedicine, v. 7, n. 26, p. 1-5, 2011.

COSENDEY, B. N.; SALOMÃO, S. R. Visão sobre as serpentes: répteis ou monstros. In: ENCONTRO NACIONAL DE PESQUISA EM EDUCAÇÃO EM CIÊNCIAS, 9, 2013, Águas de Lindóia. 2013. p. 1-3

FREITAS, M. A.; SOUZA, D. G. S. Serpentes brasileiras. Slavador: Proquigel Química, 2003. MARQUES, J. G. W. Pescando pescadores: etnoecologia abrangente no Baixo São Francisco Alagoano. São Paulo, Maceió: USP, NUPAUB, 1995. p. 101-105

MARTINS, M. R. C; MOLINA, F. B. Repteis. In: MARTINS, M. R. C. (org.). Livro vermelho da fauna brasileira ameaçada de extinção. Brasília: Ministério do Meio Ambiente, 2008. p. 326-377.

SANTOS-FITA, D.; COSTA-NETO, E. M. As interações entre os seres humanos e os animais: a contribuição da etnozoologia. Biotemas, v. 20, n. 4, p. 99-110, 2007.

SAX, B. The mythical zoo: an A-Z of animals in world myth, legend, and literature. California: Abc-clio, 2001, p. 45-59

SOUTO, F. J. B; MARQUES, M. P.; MADEIRA N. C. Patrimônio cultural e biológico: desafios e perspectivas para conservação e uso. Botucatu: UNESP, 2014. 